\title{
Immunological characterization of onion (Allium cepa) allergy
}

\author{
Marcello Albanesi ${ }^{1}$, Carlo Pasculli ${ }^{1}$, Lucia Giliberti ${ }^{1}$, Maria Pia Rossi ${ }^{1}$, Danilo Di Bona ${ }^{1}$, Maria Filomena Caiaffa ${ }^{2}$, \\ Luigi Macchia ${ }^{1}$
}

'Department of Emergency and Organ Transplantation, School and Chair of Allergology and Clinical Immunology, University of Bari-Aldo Moro, Bari, Italy

${ }^{2}$ Department of Medical and Surgical Sciences, School and Chair of Allergology and Clinical Immunology, University of Foggia, Foggia, Italy Adv Dermatol Allergol 2019; XXXVI (1): 98-103 DOI: https://doi.org/10.5114/ada.2019.82829

\begin{abstract}
Introduction: Onion (Allium cepa) handling can induce contact dermatitis, rhinoconjunctivitis and asthma. However, only sporadic reports exist on allergic reactions to onion consumption.

Aim: We describe herein a case of a 35-year-old man who had an episode of anaphylaxis following cooked onion ingestion. We evaluated onion-specific IgE, the possible cross-reactivity between onion and peach and lymphocyte proliferation in response to onion.

Material and methods: Specific IgE was evaluated using two techniques: skin test and ImmunoCAP technology. Cross-reactivity between onion and peach was evaluated by IgE-ELISA inhibition test. As for lymphocyte proliferation, blood mononuclear cells were stained with CFSE dye and cultured with an in-house onion extract. Proliferation and phenotype was assessed by flow-cytometry.

Results: The skin test and ImmunoCAP confirmed the IgE-dependent response towards onion. The incubation of the patient serum with increasing concentrations of the peach extract reduced only scarcely $(\sim 30 \%)$ onion-specific IgE. Interestingly, B cells but not T cells showed proliferation in response to onion extract.

Conclusions: In conclusion, our report shows that cooked onion can induce severe allergic reactions, suggesting the presence of thermostable components. Moreover, we applied for the first time a B-cell-based approach to the diagnosis of food allergy. This latter approach might also be applied to other allergic conditions.
\end{abstract}

Key words: food allergy, onion allergy, lymphocyte proliferation, IgE-ELISA inhibition, lipid transfer proteins.

\section{Introduction}

Onion belongs to the Allioideae, a sub-family in the family of Amaryllidaceae that includes onion (Allium cepa), garlic (A. sativum), chive (A. schoenoprasum), leek (A. ampeloprasum) and rakkyo (Allium chinense) [1]. These plants are largely used for culinary purposes worldwide and, particularly, in the Mediterranean diet. Onion can induce both immediate and delayed hypersensitivity reactions. In fact, in sensitized subjects, onion handling can induce not only rhinoconjunctivitis and asthma but also contact dermatitis [2]. However, despite its wide dietary use, only sporadic reports exist on allergic reactions to onion ingestion [3-5]. Moreover, there have been no reports yet on anaphylactic reactions following consumption of cooked onion.

In clinical practice, both skin reactivity towards food allergens and food-specific immunoglobulins $E$ (IgE) lev- els in serum are used for the diagnosis and management of food allergy [6]. Taken together, these two parameters define the global levels of allergen-specific IgE as skin reactivity is quantitatively related to mast cell bound IgE. Indeed, IgE interact via the Fc fragment with FceRI, expressed on different cell types, in particular mast cells. FceRl is a high affinity receptor that has a dissociation constant $\left(K_{d}\right)$ of $10^{-9}[6]$. As a consequence, the vast majority of IgE (i.e. the bound pool) is linked to tissue resident mast cells. This larger bound pool of IgE can be assessed only by the skin testing technique. The remaining IgE molecules (i.e. the much lesser unbound pool) circulate in plasma. In allergic subjects, the amount of unbound allergen-specific IgE may be evaluated by ImmunoCAP technology [7, 8].

Three main allergens have been characterized for onion: i) All c 3, a 12 kDa lipid transfer protein (LTP); ii) All c 4, a profilin; and iii) All c, an alliin lyase. Allergenic cross-re-

Address for correspondence: Dr. Marcello Albanesi, Department of Emergency and Organ Transplantation, Section of Allergology, School and Chair of Allergology and Clinical Immunology, University of Bari-Aldo Moro, Piazza Giulio Cesare, Policlinico, 70124 Bari, Italy, phone: +39080 5478817, fax: +39 080 5593576, e-mail: marcello.albanesi@uniba.it Received: 19.10.2017, accepted: 28.12.2017. 
activity has been demonstrated between members of the Allioideae family [9, 10]. Moreover, cross-reactivity with other food allergens such as peach was postulated [3].

\section{Aim}

We describe herein a case of a 35-year-old man who had an episode of severe systemic reaction to cooked onion ingestion, which required treatment at the emergency department. We evaluated both mast cell bound and unbound onion-specific IgE levels (along with other food and respiratory allergens) and assessed the possible cross-reactivity with peach.

Moreover, in allergic subjects, it has been recently demonstrated that a subset of circulating allergen-specific B cells, with a memory phenotype, exists. Importantly, these cells are able to proliferate in response to the cognate allergen [10].

Based on this observation, to further characterize the onion sensitization, we developed a cytofluorimetric approach seeking demonstration of proliferation of circulating B cell in response to onion extract.

\section{Material and methods}

\section{Patient}

We studied a 35-year-old man who reported an episode of anaphylaxis/severe systemic reaction (intense itching, urticaria, dyspnoea, dysphonia and malaise) a few minutes after cooked onion consumption.

\section{Quantitative skin testing}

Skin testing was carried out in a strictly quantitative fashion, in a single session, on the volar side of the forearm. A collection of 34 commercial food allergen extracts (Lofarma, Milan, Italy), 15 respiratory allergen extracts (ALKAbellò, Milan, Italy; on the back of the patient) and an inhouse semi-purified extract of onion were used (see below for extract preparation). Both commercial and in-house semi-purified onion extracts were tested in duplicate.

As for skin reactivity quantitative assessment, the area of the wheals generated was calculated as described. In order to achieve normalization, results (the duplicate for onion) were expressed in terms of the ratio between the wheal area and the histamine area, referred to as Skin Index [7-9].

The quantitative skin prick testing procedure was also carried out with both raw and microwaved cooked onion and with garlic and Muscari comosum, a locally consumed edible bulb [11].

As for the latter, we subjected $50 \mathrm{~g}$ of onion to heating treatment in a Philips M305 microwave oven at $2540 \mathrm{MHz}$ for 7 '.

\section{Preparation of onion and peach "in-house" extracts}

A suitable amount (50 g) of the edible part of fresh A. cepa was washed properly, minced and homogenated for 15 ' by a Heidolph DIAX 900 homogenizer with a Heidolph $10 \mathrm{~F}$ probe, at 25,000 rpm, on ice, in the presence of $5 \mathrm{ml}$ PBS $10 \mathrm{X} \mathrm{W} / \mathrm{O} \mathrm{Ca}{ }^{++}, 200 \mu \mathrm{l}$ ethylenediaminetetraacetic acid (EDTA) $0.5 \mathrm{M}$ and $350 \mu \mathrm{l}$ of plant cell-specific protease inhibitor cocktail (Sigma, Milan, Italy). The inhibitor cocktail contained 4-(2-aminoethyl) benzenesulfonyl fluoride hydrochloride (AEBSF), 1,10-phenantroline, pepstatin $A$, bestatin and trans-epoxysuccinylL-leucylamido-(4-guanidino)butane (E64), at unknown concentrations. The homogenate was then centrifuged at $12,000 \times \mathrm{g}$, for $20^{\prime}$ at $4^{\circ} \mathrm{C}$ and the supernatant was recovered. This step was repeated two more times. Successively, the sample was ultracentrifuged at 100,000 × g, for $2 \mathrm{~h}$, at $4^{\circ} \mathrm{C}$. Thus, $4 \mathrm{ml}$ of $100,000 \times$ g supernatant were obtained from $50 \mathrm{~g}$ of fresh $A$. cepa. The extract was kept at $-80^{\circ} \mathrm{C}$, until used.

The protein content was determined according to the colorimetric Bradford method [12].

The same procedure was used for the generation of the in-house peach extract.

\section{Serum IgE measurement}

Circulating IgE levels were measured by ImmunoCAP technology (ImmunoCAP Thermo Fischer, Milan, Italy) in serum collected from the patient.

\section{Amino acid sequence identity assessment}

The amino acid sequences of All c 3 (Q41258) and Pru p3 (AAV40850) are available in GenBank. The percentage of sequence identity was calculated using "Needle" program 6.0 version.

\section{IgE-ELISA inhibition test}

IgE-ELISA inhibition experiments were performed to evaluate the possible cross-reactivity between onion and peach extracts. To perform the IgE-ELISA inhibition experiments, $80 \mu \mathrm{l}$ of serum from the patient were preincubated for $24 \mathrm{~h}$ at $4^{\circ} \mathrm{C}$, while gently shaking, with a series of 3 samples of $20 \mu$, containing either onion or peach proteins in PBS w/o $\mathrm{Ca}^{++}$and $\mathrm{Mg}^{++}, 2.5 \mathrm{mM}$ EDTA. For both allergens, samples with an increasing protein content were used. Thus, $0.4,2$ and $8 \mu$ g, respectively for onion (auto-inhibition) and 0.23, 1.14 and $4.56 \mu \mathrm{g}$, respectively, for peach (cross-inhibition) were loaded.

Thereafter, specific-lgE levels were assessed using an ELISA-capture assay marketed by RADIM, Pomezia, Italy. To this aim, an anti-lgE coated 96-well plate was used. Fifty $\mu \mathrm{l}$ of the patient serum were incubated together with $100 \mu \mathrm{l}$ of either biotinylated onion allergen or biotinylated peach allergen (both obtained from RADIM, Pomezia, Italy). After incubation $\left(1 \mathrm{~h}\right.$, at $37^{\circ} \mathrm{C}$ ) and extensive washing, $150 \mu \mathrm{l}$ of Conjugate $\mathrm{E} 2$ was added to all wells and incubated for 30 $\min$, at $37^{\circ} \mathrm{C}$, in the dark. Upon washing, the addition of $100 \mu \mathrm{l}$ of Substrate Solution revealed the presence of specific IgE. Optical density (O.D.) measurement was carried 

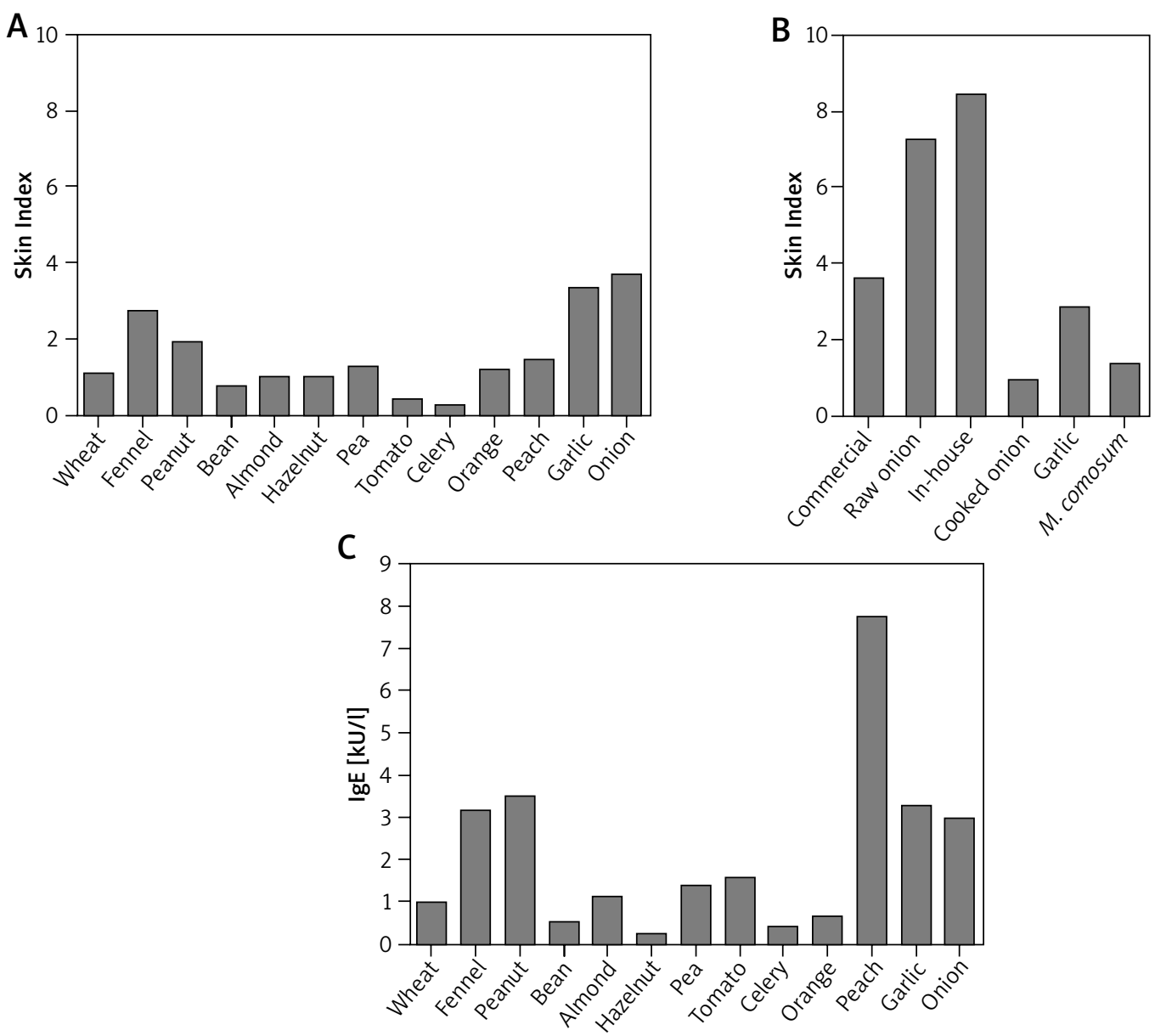

Figure 1. Evaluation of onion-specific IgE. A - Quantitative skin prick tests for a commercially available array of food allergens. B - Quantitative skin prick tests for a commercially available onion extract and semi-purified in-house onion extract; prick tests with raw and cooked onion, raw garlic and $M$. comosum; C - circulating food allergen-specific IgE, as measured by ImmunoCAP. The Skin Index represents the ratio between the area of the allergen wheal and the area of the exogenous histamine reference wheal

out at $\lambda 450 \mathrm{~nm}$. To this aim, a microplate reader (Biorad, model 450, Milan, Italy) was used.

\section{Peripheral blood mononuclear cells (PBMCs)} preparation, carboxyfluorescein diacetate succinimidyl ester labelling (CFSE) and flow cytometry

The PMCs were obtained from the patient and 2 nonallergic healthy donors buffy coats by dextran sedimentation followed by centrifugation on Lymphoprep (Nycomed Pharma, Oslo, Norway) and hypotonic lysis of contaminating erythrocytes.

Peripheral blood mononuclear cells (PBMCs) were labelled with $1 \mu \mathrm{M}$ of the cytoplasmic dye carboxyfluorescein diacetate succinimidyl ester (CFSE) (Sigma). CFSEstained PBMCs $\left(2 \times 10^{6}\right.$ cells $\left./ \mathrm{ml}\right)$ were cultured in RPMI media, with streptomycin $(100 \mathrm{U} / \mathrm{ml})$, and supplemented with $5 \%$ autologous plasma. Antigen titration studies of cultures incubated for 3 and 5 days, respectively, were performed to optimize culture conditions. Thus, $2 \times 10^{5}$ cell samples were distributed to triplicate wells of a 96 - well flat-bottom plate and cultured (200 $\mu$ l final volume) in the presence of an in-house onion extract $(10 \mu \mathrm{g} / \mathrm{ml})$.

After 3-day culture, lymphocyte subsets were analysed by flow cytometry using: anti-CD3-Allophycocyanin (eBioscience) or anti-CD19-Pacific Blue (eBioscience). Actively proliferating cells were distinguished by excluding cells with high CFSE.

\section{Ethics approval and consent to participate}

This study was approved by the ethical committee of “Ospedali Riuniti-Foggia”, Via Luigi Pinto 1, 70100, Foggia.

Oral informed consent was obtained and recorded in the clinical file of the patient.

\section{Results}

\section{Onion-specific IgE response}

As shown in Figure $1 \mathrm{~A}$, the skin prick testing technique revealed multiple allergenic sensitizations. In par- 

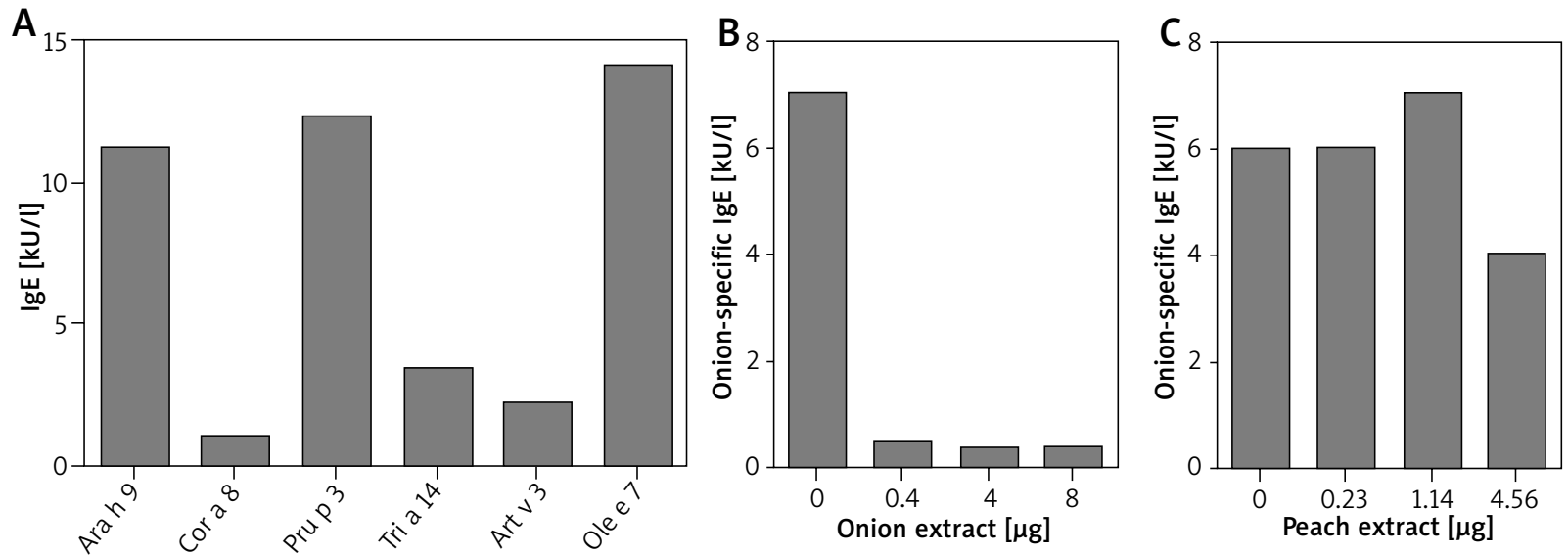

D

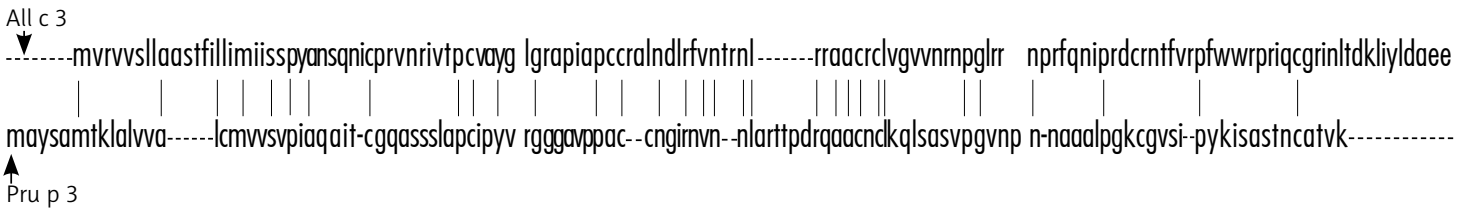

Figure 2. Evaluation of onion cross-reactivity. A - Circulating LTP-specific IgE as measured by ImmunoCAP. B - IgE-ELISA inhibition by onion proteins. Serum of the patient was incubated for $24 \mathrm{~h}$ at $4^{\circ} \mathrm{C}$ with the indicated amount of onion protein from an in-house extract. C - IgE-ELISA inhibition by peach proteins. Serum of the patient was incubated for $24 \mathrm{~h}$ at $4^{\circ} \mathrm{C}$ with the indicated amount of peach protein from an in-house extract. D - All c 3 and Pru p 3 amino acid sequence identity. Vertical lines between the two sequences indicate the identical amino acid residues

ticular, the Skin Index in response to the commercial onion extract was 3.66 (Figures 1 A, B). Interestingly, the Skin Index obtained in response to raw onion was 2-fold higher compared to the commercial extract (i.e. 7.25). Likewise, the Skin Index obtained after the skin test performed with the in-house extract was 8.15 (Figure 1 B).

As mentioned before, the patient developed an anaphylactic reaction following the ingestion of cooked onion. In order to test the allergenic activity of cooked onion we also performed skin testing with cooked onion. Importantly, although substantially reduced, cooked onion was still able to induce a valid cutaneous response with a Skin Index of 0.91 (Figure 1 B). Garlic (Figures 1 A, B) and $M$. comosum (Figure 1 B) were also positive.

Finally, we evaluated the presence of soluble specific IgE towards the same food allergens deemed positive with skin testing, in the patient's serum. Thus, circulating IgE levels for all these allergens were detected (Figure 1 C). The results obtained confirmed the poly-sensitization status revealed with skin testing and confirmed the presence of onion-specific lgE $(3.99 \mathrm{kU} / \mathrm{l})$. Notably, the peachspecific lgE level was $7.71 \mathrm{kU} / \mathrm{l}$, as opposed to more modest skin reactivity.

Skin tests for an array of 15 respiratory allergens were also performed, revealing sensitizations for: Dermatophagoides pteronyssinus (Skin Index: 2.5); D. farinae (3.5); Olea europaea (2.2); Parietaria judaica (0.3); Artemisia vulgaris (0.35); Cupressus arizonica (1.3). The relevant RAST values were (in kU/L) 20.2; 11.5; 13.8; 0.42; 0.67; 0.30, respectively. Total IgE was $153 \mathrm{kU} / \mathrm{l}$.

\section{Onion and peach cross-reactivity assessment}

Three allergens have been characterized for onion. In particular, All c 3, one of the main onion allergens is a LTP that might show cross-reactivity with other LTPs. Thus, in the serum of the patient we evaluated the presence of specific IgE for LTPs of the allergens that were deemed positive in both skin tests and ImmunoCAP. In particular, as shown in Figure 2 A, we found IgE for Ara h 9 (11.2 kU/l; LTP from peanuts), Cor a 8 (1.07 kU/l; LTP from hazelnut), Pru p 3 (12.3 kU/l; LTP from peach), Tri a 14 (3.4 kU/l; LTP from wheat), Art v 3 (2.18 kU/l; LTP from $A$. absinthium) and Ole e 7 (14.1 kU/l; LTP from O. europaea).

In order to investigate the possible cross-reactivity between onion and peach we performed IgE-ELISA inhibition tests with in-house semi-purified onion and peach extracts. Pre-incubation of the patient serum with increasing concentrations of onion proteins abolished the anti-onion IgE titre already after pre-incubation with $0.4 \mathrm{mg}$ of proteins (Figure 2 B). In contrast, the anti-onion IgE titre was only scarcely reduced upon pre-incubation with an excess of peach proteins (4.56 $\mu$ g; Figure $2 \mathrm{C}$ ). Accordingly, inhibition of IgE-ELISA for peach with onion extract led to no decrease in the peach-specific lgE titres (data not shown).

In order to corroborate these findings, we assessed the amino acid sequence homology of All c 3 and 

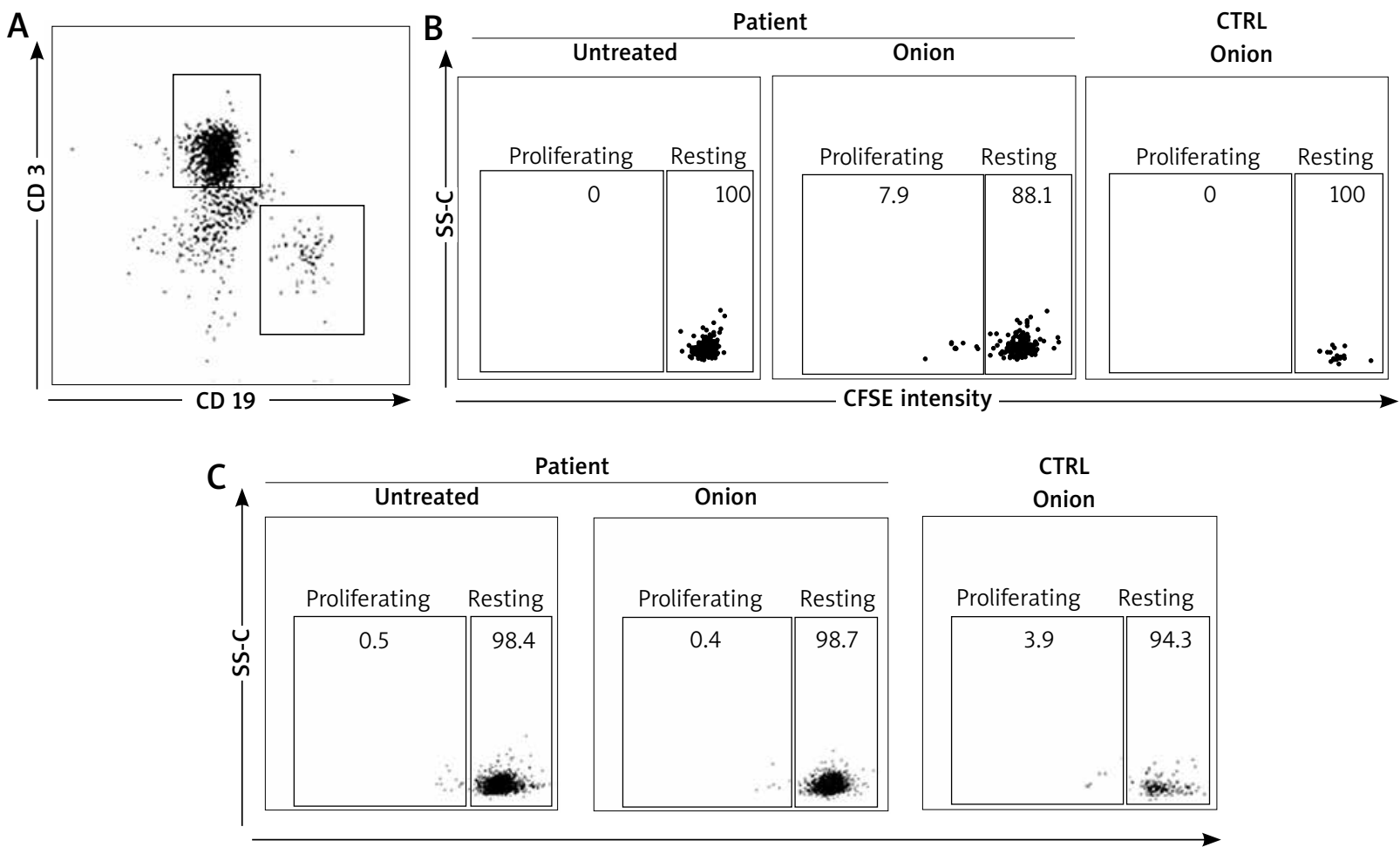

Figure 3. Onion-specific B-cell proliferation. A - Gating strategy for CD 19 and CD 3 cells. Representative CD 19+ (B) and CD 3+ (C) cell proliferation assessed by reduction of CFSE intensity for the patient compared to healthy controls. Experiments were done in triplicates

Pru p 3. Interestingly, these two proteins share only $23 \%$ of sequence identity (Figure 2 D).

\section{B cell specifically proliferate in response to onion extract}

The existence of circulating allergen-specific B cells was previously demonstrated in the allergic subject. These cells have a memory phenotype and are able to proliferate upon the cognate allergen encounter [10].

In order to investigate this possibility, we sought for onion-specific B cells in the patient blood. Patient lymphocytes were stained with CFSE and assessed for their capacity to proliferate in response to the semi-purified in-house onion extract $(10 \mu \mathrm{g})$. B cells were identified on the basis of the expression of the B cell marker CD19, whereas $T$ cells were identified by the CD3 marker (Figure 3 A). Importantly, CD19+ (Figure 3 B) but not $\mathrm{CD}^{+}$cells (Figure 3 C) of the patient proliferated when incubated with the semi-purified in-house onion extract (Figures 3 A, B). Proliferation was not observed in healthy controls (either $\mathrm{CD}_{19}{ }^{+}$or $\mathrm{CD}^{+}$cells).

\section{Discusssion}

Onion and other edible plants belonging to the Allioideae family are widely used in the Mediterranean diet, as well as in other diets, either raw or cooked. So far, despite its large consumption, allergic reactions due to onion ingestion remain anecdotal and, to our knowledge, severe allergic reactions following cooked onion ingestion have never been described. Moreover, it was reported that patients that experienced an allergic reaction to raw onion ingestion tolerated cooked onion [2-5].

In our work we describe a case of a severe allergic reaction after cooked onion ingestion.

We studied the allergic response towards onion using different techniques. At first we performed skin prick tests in order to assess the mast-cell bound pool of onion-specific IgE. However, although a limited number of well-standardized food allergen extracts exist, most food allergen extracts are little or non-standardized. Thus, the skin reactivity and thereby the evaluation of the amount of allergen specific IgE might be influenced by the quality of the extract (e.g. protein concentration, protein denaturation etc.). Moreover, the composition of non-standardized, commercially available extracts may vary greatly between manufacturers. With respect to onion, we tested both a commercial onion extract and an in-house onion extract and, in order to achieve normalization, we then expressed the results obtained as a Skin Index, previously defined as the ratio between the area of the wheal generated by the allergen and the area of the wheal generated by exogenous histamine [7-9]. Importantly, we found that 
the Skin Index obtained with the in-house onion extract was higher compared to the one obtained with the commercial extract. Our results confirm that extract quality matters in food allergy diagnosis.

In order to test the allergenic activity of cooked onion we then performed skin tests with both raw and cooked onion. It is worth noticing that the allergenic activity of onion after heating treatment was reduced but not lost, suggesting the existence of one or more thermostable components (Figure $1 \mathrm{~B}$ ). Thus, among the characterized onion allergens (All c 3, All c 4, All c), All c 3 belongs to the LTP superfamily and should thereby be considered thermostable [13-16]. In the case reported, this protein could perhaps be responsible for the clinical symptoms experienced by the patient.

As for the postulated cross-reactivity between onion and peach, although some reports seem to convincingly suggest that [3], our findings indicate that this cross reactivity is marginal since an excess of peach proteins inhibited the IgE-ELISA for onion by approximately $30 \%$ only (Figure 2 C). Amino acid sequence identity data ( 23\%) seem to support this interpretation.

Diagnosis in food allergy may sometimes be difficult as pointed out by the skin test results (see above), thereby new investigational tools may be helpful. It is well known that production of IgE involves B cell and, in particular, antibody-producing plasma-cells. Aside plasma-cells, in pollen-allergic subjects, it has been recently demonstrated that the circulating allergen-specific B cell population exists [10]. Importantly, these cells have a memory phenotype (i.e. $\mathrm{CD}_{19}{ }^{+}, \mathrm{CD}_{2} \mathrm{O}^{+}$and $\mathrm{CD} 27^{+}$). Thus, upon encounter with the cognate allergen, they can proliferate and eventually give rise to antibody-producing plasma cells. Taken into account these observations, in order to confirm the onion sensitization in our patient, we developed a lymphocyte proliferation test using flow cytometry technique. In fact, we found for the first time an onion-specific $\mathrm{CD} 19^{+}$cell population, able to proliferate in response to onion extract (Figure $3 \mathrm{~B}$ ). This latter cell population is not present in healthy controls. These findings are further validated by the fact that similar observations could not be done with CD $3^{+}$cells.

\section{Conclusions}

Our report shows that cooked onion can induce severe allergic reactions that are likely due to the LTP All c 3, a thermostable allergen. Moreover, we applied for the first time a B-cell-based approach to the diagnosis of food allergy. Importantly, this latter approach might also be applied to other allergic conditions such as hymenoptera venom allergy or drug allergy.

\section{Conflict of interest}

The authors declare no conflict of interest.

\section{References}

1. Sanchez-Hernandez MC, Hernandez M, Delgado J, et al. Allergenic cross reactivity in the Liliaceae family. Allergy 2000; 55: 297-308.

2. Valdivieso R, Subiza J,Varela-Losada S, et al. Bronchial asthma, rhynoconjunctivitis and contact dermatitis caused by onion. J Allergy Clin Immunol 1994; 94: 928-30.

3. Asero R, Mistrello G, Roncarolo D, Amato S. A case of onion allergy. J Allegy Clin Immunol 2001; 108: 309-10.

4. Arena A, Cislaghi C, Falagiani P. Anaphylactic reaction to the ingestion of raw onion: a case report. Allergol Immunopathol (Madrid) 2000; 28: 287-9.

5. Antolin-Amerigo D, Gandolfo-Cano M, Gonzalez-de Olano D, et al. Occupational allergy to Spanish omelette. J Investig Allergol Clin Immunol 2012; 22: 522-3.

6. Adkinson N, Bochner B, Burks A, et al. (eds.). Middleton's Allergy. $8^{\text {th }}$ edn. 2014.

7. Corallino M, Nico A, Kourtis G, et al. Skin testing technique and precision in stinging insect allergy. J Clin Nurs 2007; 16: 1256-64.

8. Macchia L, Caiaffa MF, Di Felice G, et al. Changes in skin reactivity, specific IgE and IgG levels after one year of immunotherapy in olive pollinosis. Allergy 1991; 46: 410-8.

9. Enrique E, Malek T, De Mateo JA, et al. Involvement of lipid transfer protein in onion allergy. Ann Allergy Asthma Immunol 2007; 98: 202.

10. Wong KJ, Timbrell V, Xi Y, et al. IgE+ B cells are scarce, but allergen-specific $B$ cells with a memory phenotype circulate in patients with allergic rhinitis. Allergy 2015; 70: 420-8.

11. Foti C, Nettis E, Cassano N, et al. Allergy to Muscari comosum bulb. Allergy 2007; 62: 1217-8.

12. Bradford MM. A rapid and sensitive method for the quantitation of microgram quantities of protein utilizing the principle of protein-dye binding. Anal Biochem 1976; 72: 248-54.

13. Kao SH, Hsu CH, Su SN, et al. Identification and immunology characterization of an allergen Alyin lyase from garlic (Alium Sativum). J Allergy Clin Immunol 2004; 113: 161-8.

14. Matricardi PM, Kleine-Tebbe J, Hoffmann HJ, et al. EAACI molecular allergology user's guide. 2016; Part C. Pediatr. Allergy Immunol 2016; 27 Suppl 23: 1-250.

15. Salcedo G, Sanchez-Monge R, Diaz-Perales A, et al. Plant non-specific lipid transfer proteins as food and pollen allergens. Clin Exp Allergy 2004; 34: 1336-41.

16. Cavatorta V, Sforza S, Aquino G, et al. In vitro gastrointestinal digestion of the major peach allergen Pru p3, a lipid transfer protein: molecular characterization of the products and assessment of their IgE binding abilities. Mol Nut Food Res 2010; 54: 1452-7. 